\title{
Manipulating human-oriented dictionaries with very simple tools
}

\author{
Jean Gaschler \& Mathieu Lafourcade \\ (Jean.Gaschlereimacy.fr - Mathieu.raEourcadeeinag. Er) \\ GETA, IMAG-campus (UJI \& CNRS) \\ BP' 53, F-38041 GIRIENOBILE Cedex (0)
}

\begin{abstract}
It is possible to manipulate real-size human-oriented dictionaries on a Macintosh by using only very simple tools. Our methodology has been applied in the construction of a French-linglish-Malay dictionary. This dictionary has been obtained by "crossing" semi-automatically two bilingual dictionaties. "To revise the dictionary, as well as to obtain a publishable paper form and an on-line electronic form, we use only Microsoft Word $^{\mathrm{TM}}$, a specialized language for writing transcriptors and a small but powerful dictionary tool.
\end{abstract}

\section{Keyword}

I.inguistic tools, 'Transducers, Dictionary management, Iluman-oriented dictionaries.

\section{Introduction}

In collaboration with University Sains Malaysia (USM), we are working on a liench-Inglish-Malay human-oriented dictionary (FIEM project) obtained by "crossing" French-English and linglish-Malay dictionaries.

Taking into account the reluctance of lexicographers to revise dictionaries through database interfaces (IBASSIII ${ }^{\mathrm{YM}}$ or $4 \mathrm{II}^{\mathrm{TM}}$ ), we have developed a methoklology based on using only very simple tools. For editing, we use Word and its styling facility, because no editor of structured document is available on the Macintosh. For importing and exporting, we use I.T, a simple speciatized language for writing transcriptors, and transform between represcntations (normalized $\Lambda$ SCII, RTF, cte.). Iinally, we have developed ALEX, a diclionary toot, to support the electronic form. The methods defined have been applied on the FEM dictionary. They concem the correction of errors which can appears in a matumally busil dictionary and the formatting of this dictionary.

We introduce first in more details the situation we face with the IIIM project. We expose the goals we tend to reach. Then we gives our generic methods and their applications to the specilic case of the FISM dictionary.

\section{Situation}

\section{Presentation}

The FEM dictionary is composed of two parts: a general one $(12,000$ entries) and a specific one for computer-science terminology (2,300 terms). Both paper and electronic forms will be produced by mid-94.

We have initially received ASCII files obtained firstly by optical characters recognition and corrected manually in which the informations of the French-Fnglish and English-Malay dictionaries have been crossed.

\section{Logical form}

The printed form of dictionaries reflect their internal structure (Boguraev 1990, Byrd, Cakolari, Chodorow \& al. 1987). This structure can be modelized with a logical lom which gives the sequence of the informations contained by the dictionary. This logieal form contains entries, prononciation parts, spelling variants, grammatical categories, semantics information, sub-entries, etc. We have defined a logical form of the article in the lis $M$ dictionary (lig. 1).

\begin{tabular}{|c|c|}
\hline 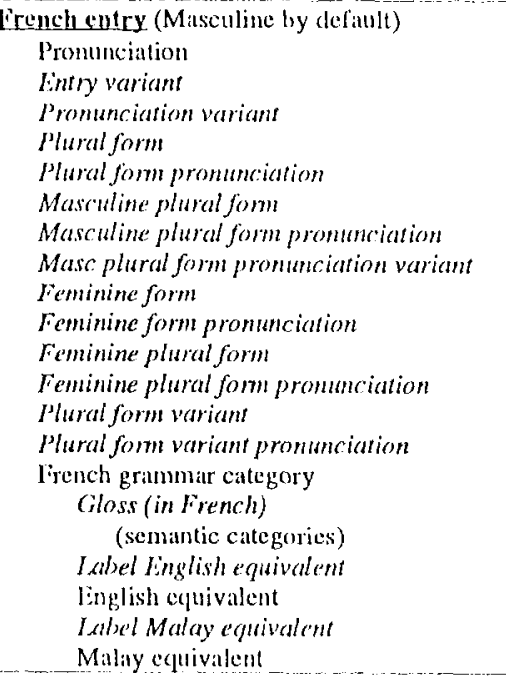 & $\begin{array}{l}\text { Main part of } \\
\text { an entry }\end{array}$ \\
\hline $\begin{array}{l}\text { French phrase (such as compound words) } \\
\text { English plrase equivalent } \\
\text { Malay phrase equivalem }\end{array}$ & $\begin{array}{l}\text { Illustrative } \\
\text { phrases }\end{array}$ \\
\hline $\begin{array}{l}\text { Sub-enty (in French) } \\
\quad \text { (with the same stiucture as an entry) }\end{array}$ & Sub-entries \\
\hline $\begin{array}{l}\text { Cross-reference marker } \\
\text { Cross-refcrence entry }\end{array}$ & $\begin{array}{l}\text { Cross } \\
\text { references }\end{array}$ \\
\hline
\end{tabular}

\section{ASCII normalized external form}

$A$ label is linked with every type of information of the logical form and is included in the initial ASCII files. Thus, USM have obtained basic entries such as this given in fig. 2 which corresponds to the french entry "accident" (the label 'e' corresponds to the French entry, 'pen' to pronunciation, 'c' to grammatical calcgory, etc. 


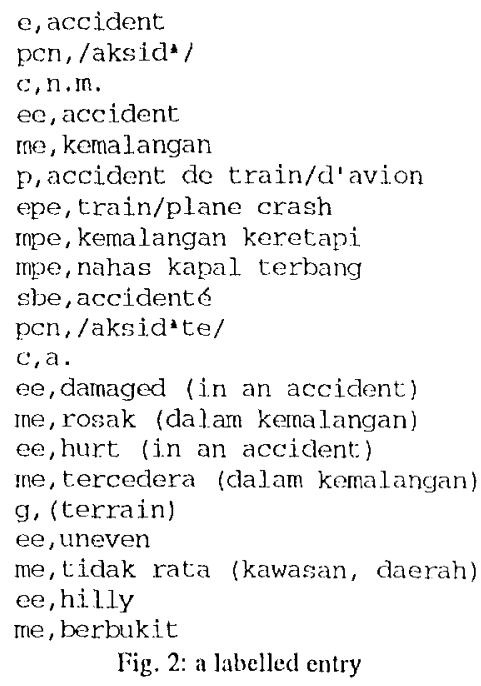

Fig. 2: a labelled entry

\section{Goals}

We pursue four goals in this project. They are listed below in order of importance.

\section{Paper formatting}

Our first aim is to produce from the ASCII normalized form a paper form of the FIM diclionary with a format approaching that of usual dictionaries (fig. 3). This involves the introduction in the format of fonts, styles, ete.

accident laksidā/n.m. accident: kemalangan, (kejadian) tidak sengaja, (kejadian) secara kebetulan - accident de $t \mathrm{rain} / \mathrm{d}^{\prime}$ avion train/plane crash : kemalangan keretapi, nahas kapal terbang --- acciclenté /aksidãte/ $a$. damaged (in an acciclent): rosak (dalam kemalangan) hurt (in an accident): tercedera (dalam kemalangan) (torrain) uneven: tidak rata (kawasan, daerah) hilly: berbukit.

Fig. 3 : an entry of the publishahle paper lFM dictionary

\section{Electronic formatting}

We also produce an electronic form. 'This efectronic dictionary is sumported by of a generic multilingual dictionary tool, NLEX. "lhe problem is to keep as much as possible of the logical form, so ats to allow logical aceess such as searching on multiple keys, sorting, etc.

\section{Dictionary revision}

"Crossing" of the French-Fnglish and Fugglish-Malay dietionaries has been made manually by people who were not thuent in French. Thus, some errors remain in both the logical structure and in the content. These errors have to be corrected before producing the final paper form of the FEM dictionary.

\section{Phonetic codes conversion}

USM did not use the standard phonetic transeription (international phonetic alphabet - IP $\Lambda$ ), but a local transcription using certain characters of the Times ${ }^{\mathrm{TM}}$ font, which looks like characters of the IP $\wedge$. 'These characters have high $\Lambda$ SCII code (128 to 256 ), thus this rendering is different according to the font. To be portable to $\mathrm{PC}$ for instance, the files must contain only lower $\mathrm{ASCI}$ characters (32 to 128).

\section{Methodology}

Our methodology is generic enough to be applied to other projects dealing with the construction of real-size publishable human-oriented dictionaries. 'The methodology is based on the use of simple but powerful ix)ls.

\section{Use of an editor for correcting errors}

The problem is to lind an appropriate software for this work. The first type of soltware is databases but our experiences with them (we have used (BASSE III and 4D) show that lexicographers don't like to work through DataBase Management Systems. They want to use the same word processor to see the texts they want to index and to construct the dictionary.

The most practical tool would be an editor of strictured documents like Grif' (André, Furuta \& Quint 1989, Plan \& Boitet 1992) which can manage the logical form of the dictionary. However, such editors ate complex 10 learn and are not yet available on micros as they require large computing ressources. IIcnee, we use Word, a widely available commercial word processor.

We approach this notion of structured documents by using Word's "styling" facility. $\wedge$ Word style is a group of paragraph and characters format with a name (c.g. the title of this section has the style "litlel' which includes the information about the rendering of this title). We associate a particular style to each logical type of information in the dictionary.

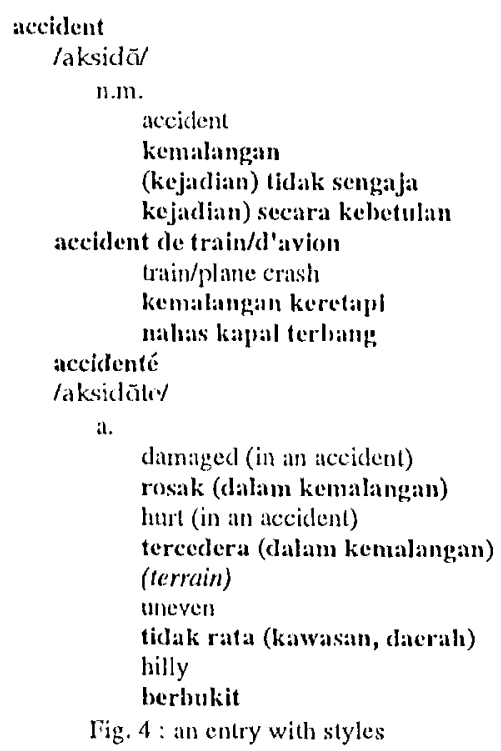

\section{Use of an SLLP for converting formats}

To convert the initial normalized $\Lambda$ SCII external form (fig. 2) in a printable lorm (lig. 3), we propose some solutions: 
the first solution is to use Word's macro facility. Unfortunately, that facility is only available on the $P C$ version, and we lound it very clumsy to constantly exchange large files between the $\mathrm{P} C \mathrm{C}$, and the Macintosh, not speaking of unexpected chatacter transformation in the phonctic font.

- the second solution is to use transducers, but the commercial transcriptors available ate only based on direct correspondences. They camnot take into account a forward context and they generally have no variables (or notion of state). llus, hey atre not powerful enough for the problenss at hand.

We used I'T (L angunge of Transcriptions), a Specialized language for linguistic Programming for writting transcriptors.

I.' transducers have one input tape with two reading heads (one standard head and one forward head) and one writing head. 'l'hey can also handle variables and produce side effects. Thus, this kind of transcriptors is not reversible in general.

There have been previous versions of LT (Tepage 1986) The L'T used in our work has been implemented on Macintosh with CLOS (Common Lisp Object System) (Lafoureade 1993) The realization is based mainly on Lisp Macroprogramming on the top of an Automaton Manager.

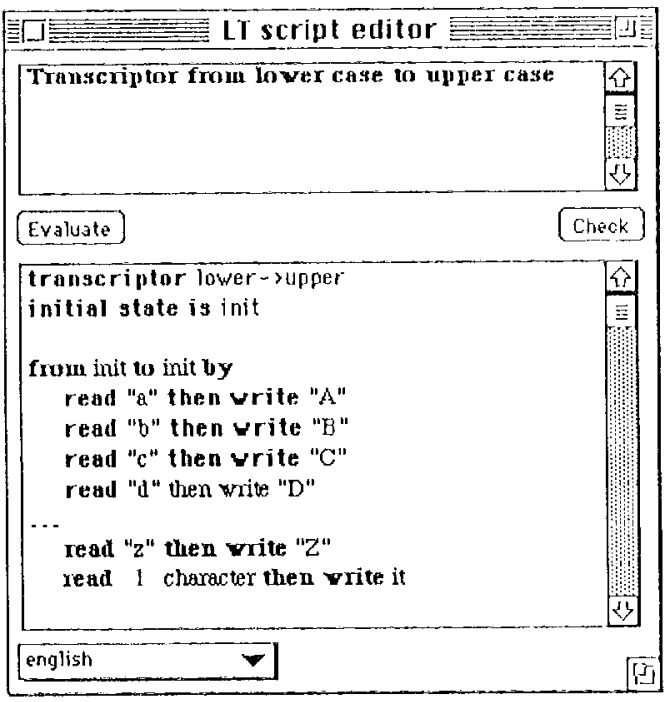

lïg. 5: an L.T transcriptor example

With IT, we have easily written all necessiry converters.

\section{- Phonetic transcriptions}

These conversions first coneen the problem of special characters used in some fonts, especially the chatracters used at USM (standard macintosh fonts, i.c. comricr on times) to approximate the international phometic alphabet (Il' $A$ ). For example, the "sign (as in /aksid"/) appears only in a standlatd macintosh font.

We have thus delined three formats. Whit is the initial form of the Word files in a standard macintosh font (liles built at USM). Th2 is the format where special chanaters are replaced by others which appear in all usmal fonts (characters corresponding with the letters, the numbers and with the 't', '-' signs, i,e. 7-bits ASCII). 'Th is ASCYI coding authorises a sate exchange between Macintoshes and P'S

$$
\text { aborigene: /ab }>\text { ri3 } \sum n / \rightarrow / A B O R I J I+N /
$$

To transcript from the ph1 wo the phe formats, we use the IT tanscriptor thitolkz. An excerpt is given below.

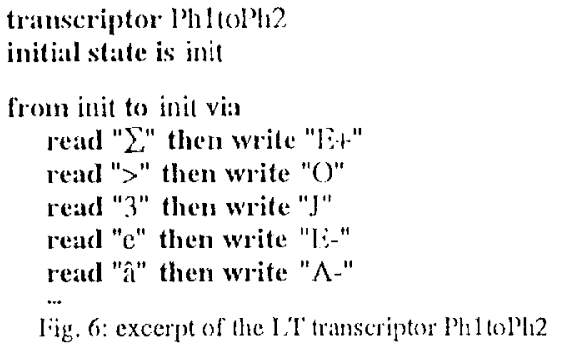

Ph.3 is the IP $\wedge$ phonetic fomat. Pall Plon is the font used for this IPA trunscription. The problem is to assign this font onfy to the lines which correspond to phonetic transeription, and hence bo deleminate the right.

llere, we work on the R'll: (Rich Text lomtal) lormat, directly produced by Word, which records all the intormations describing Word documents (styles, fonts and oher informations as italic, bold, etc).

Figure 7 presents the RTI: form for the line 'e, accident'. IsO corresponds to the 'Normal' style of Word and V20 corresponds to the standard macintosh lont.

$$
\begin{aligned}
& \text { Jpardiplain Iso lf20 e, accident lpar } \\
& \text { Beginning of paragraph End of paragraph } \\
& \text { Style number } \\
& \text { Other informations } \\
& \text { Text of the paragraph }
\end{aligned}
$$

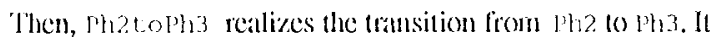
transforms the RTP form of the lines corresponding to pronunciation (phonetic) by converling the fimes font colde (120) to the Patl'son font cole (VI 138) and eateh chatracter in Ph2 form to the $1{ }^{2} \wedge$ form.

$$
\text { aborigene: /ABSORIIIIN N/ } \rightarrow \text { /aborigen/ }
$$

An excerpt of phat ophs is given below. 'The code RT?: lab corresponds to the character "' in the Pallhon font, l'bl to ' $(x)^{\prime}$, ctc.

\section{transcriptor Pli2toPli3}

initial state is init

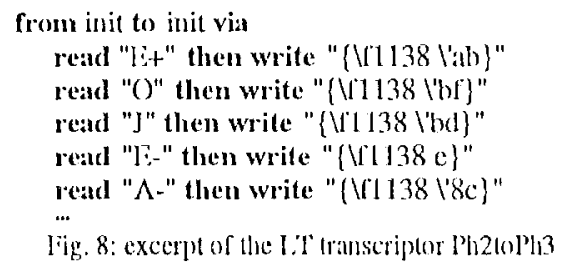




\section{- External format}

The first conversion type was about the problem of special characters rendering in the dictionary. 'The second concerns the external format of the dictionary. We have defined three formats:

- AN: the ASCII normalized form which corresponds to the initial files ( $\mathrm{Ph} 1$ ), these files with phonetic encoling (Ph2) and these files in the RTl format (Ph3).

- WT: the Word transitory form which corresponds to the stylized files with phonetic encoding (Ph2) and and these files in the RTT format (Ph3) (lig. 4).

- WP: the Word printing form (fig. 3) in which we have canceled every informations about styles but we kept the other informations as fonts code and other chancters formats ( $\mathrm{Ph} 3$ ).

The conversions between $A N, W^{\prime} \Gamma$ and $W P$ forms are made with I.T transcriptors.

\section{Use of a dictionary tool}

Alex is a simple and easy to use generic dictionary tool. Its functionalities are quite classical (inserting and deleting items, sorting, searching). The interesting features are the possibility to index a base on several keys and to search according to these keys or the content of any non-indexed entry (although it is slower).

Entries can be structured objects and searches can be done in function of the values of the features. $A$ same base can handle heterogeneous objects.

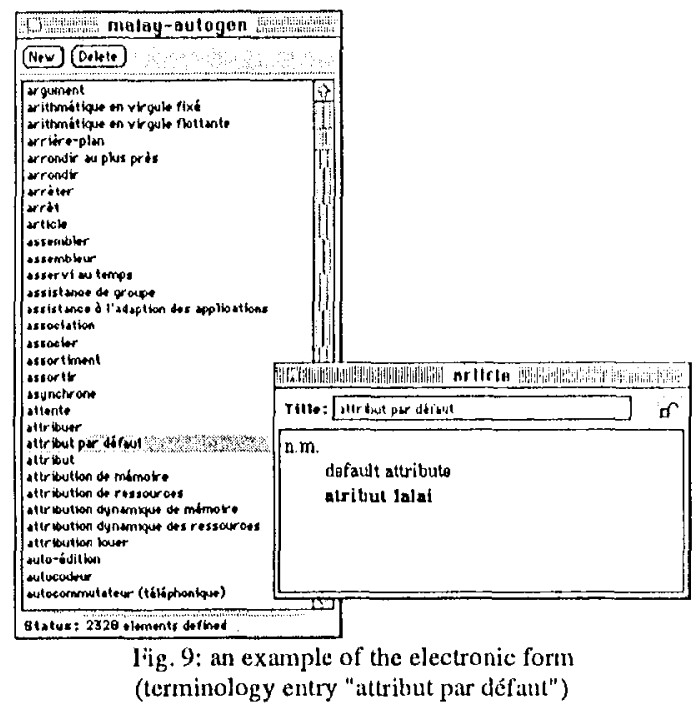

It is possible to pilot ALF $X$ remotely (instead of interacting with it via the user-interface) and this method has been used to fill the FEM electronic base.

To do so, we have written an LT transcriptor with strong side effects on ALJXX. The goal, here, was not to produce a result in term of a transcripted file, but instend to read a lile and produce actions on the AIJPX base. As any dialect of LT can mix Lisp commands in their script, it was possible to make these tools cooperate.

\section{Conclusion}

The methodology for manipulating human-oriented dictionaries presented in this paper is based on simple but powerful tools which can be used by lexicographers who don't want to spend much lime learning how to use structured documents editors and even less, how to program in DBMS. We use Word, a commercial word processor; LT, a language of transcriptions; $\Lambda \mathrm{LLX}$, a dictionary tool. Contrary to our initial fears, these simple tools proved very convenient, and powertinl enough for the tasks at hand.

$\mathrm{L}, \mathrm{T}$ and $\Lambda \mathrm{LEX}$ will soon be available by anonymous $\mathrm{ftp}$ at cambridge.apple.com.

\section{Acknowledgements}

We are grateful to Chuah $\mathrm{C}$. Kim and Zarin $\mathrm{Y}$. from the University Sains Malaysia for their patience and their corrections of the Malay part of the IISM dictionary. We wish to thank C. Boitet, II. Blanchon, C. Serasset and other colleagues from GETA, for their support, their help and their remarks. All remaining deficiencies atte, of course, ours.

\section{References}

Andre, J., R. Furuta and V. Quint (1989) Structured Documents. Cambridge University Press, Cambridge, $220 \mathrm{p}$.

Boguraev, B. (1990) Data Models for Lexicon Acquisition. Proc. International Workshop on Electronic Dictionaries, November 8-9, 1990, vol. $1 / 1, \mathrm{pp} 70-86$.

Byrd, R. J., N. Calzolari, M. S. Chodorow, J. I. Klavans, M. S. Neff and O. A. Rizk (1987) Tools and Method for Computational Linguitics. Computational Linguitics, 13/3-4, pp. 219-240.

Lafourcade, M. (1993) Inside LT, GETA, IMAG, Techuical Report GITA, September 93, $47 \mathrm{p}$.

Lcpage, Y. (1986) A language for transcriptions. Proc. COLING-86, Bom, IKS, pp 402-404.

Phatn, II. K. and C. Boilet (1992) Multilinguization of an editor for structured documents. Application to a trilingual dictionary. Proc. COLIN(i-9), Nantes, juillet 1992, C. Boitcl, el., ^Cl, vol. 3/4, pp 966 971. 